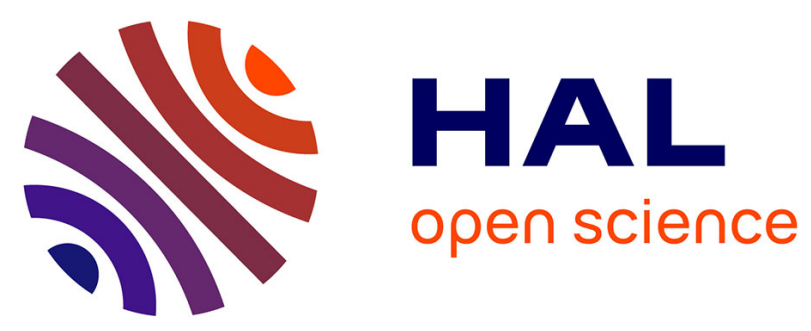

\title{
LOW AND INTERMEDIATE ENERGY HEAVY ION COLLISIONS IN THE SEMI-CLASSICAL MICROSCOPIC DESCRIPTION
}

\author{
C. Gregoire, B. Remaud, F. Sebille, L. Vinet, D. Jacquet
}

\section{To cite this version:}

C. Gregoire, B. Remaud, F. Sebille, L. Vinet, D. Jacquet. LOW AND INTERMEDIATE ENERGY HEAVY ION COLLISIONS IN THE SEMI-CLASSICAL MICROSCOPIC DESCRIPTION. International Workshop on Semiclassical and Phase Space Approaches to the Dynamics of the Nucleus, 1987, Aussois, France. pp.C2-203-C2-209, 10.1051/jphyscol:1987229 . jpa-00226496

\section{HAL Id: jpa-00226496 https://hal.science/jpa-00226496}

Submitted on 1 Jan 1987

HAL is a multi-disciplinary open access archive for the deposit and dissemination of scientific research documents, whether they are published or not. The documents may come from teaching and research institutions in France or abroad, or from public or private research centers.
L'archive ouverte pluridisciplinaire HAL, est destinée au dépôt et à la diffusion de documents scientifiques de niveau recherche, publiés ou non, émanant des établissements d'enseignement et de recherche français ou étrangers, des laboratoires publics ou privés. 


\title{
LOW AND INTERMEDIATE ENERGY HEAVY ION COLLISIONS IN THE SEMI-CLASSICAL MICROSCOPIC DESCRIPTION
}

\author{
C. GRÉGOIRE, B. REMAUD*, F. SÉBILLE**, L. VINET*** and \\ D. JACQUET ${ }^{*}$
}

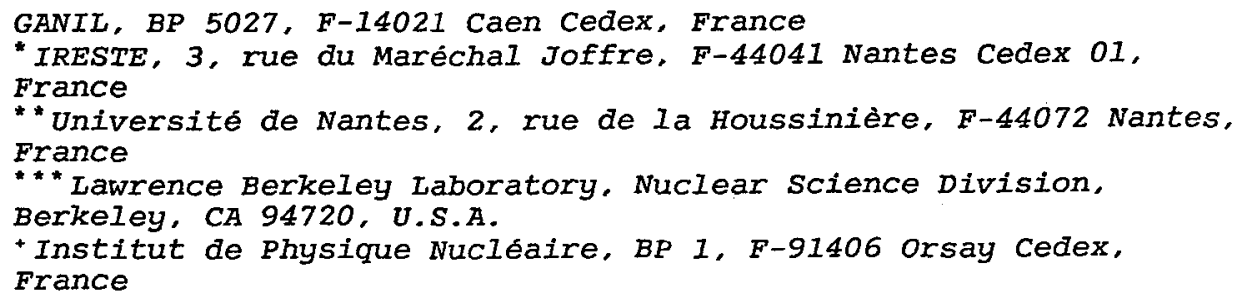

Résumé : Cette contribution est consacré à la description des collisions centrales ét périphériques à l'aide 'd'une dynamique Landau-Vlasov. Pour les collisions périphériques aux énergies intermédiaires, les corrélations masse-masse, les énergies moyennes des quasi-projectiles et les distributions anguiaires sont obtenues et comparés avec les données expérimentales. Pour les collisions centrales, on montre que la fenêtre de fusion de TDHF à basse énergie disparait avec l'introduction d'une intéraction résiduelle. Au-delà de $20 \mathrm{MeV} / \mathrm{u}$, la fusion incomplète est décrite avec le transfert d'impulsion et les déformations nucléaires associées. Le couplage aux états du continuum est analysé dans les dynariques Vlasov et Landau-Vlasov. L'intéraction Coulombienne étant incorporée, nous présentons des résultats sur le transfert d'isospin et l'excitation du mode dipolaire isovectoriel au voisinage et au-dessus de la barrière coulombienne. quelques perspectives pour 1 'étude d'observables physiques' sont finalement tracées.

Abstract : It is shown how peripheral and central heavy-ion collisions can be described by Landau-Vlasov dynamics. For peripheral collisions at intermediate energies, mass-mass correlations, ejectile mean energies and angular distributions are obtained and compared with fragmentation data. For central collisions, one shows that the collision term destroys the TDHF property of transparency at low impact parameters for collisions close from the Coulomb barrier. Above $20 \mathrm{MeV} / \mathrm{u}$ incomplete fusion is described with associated linear momentum transfer and nuclear deformations. One exhibits how coupling to the continuum is obtained in Vlasov and Landau-Vlasov dynamics. Coulomb interaction being taken into account, we present also results concerning the isospin transfer and the excitation of the isovector dipole mode near and well above the Coulomb barrier. Some perspectives to further studies of physical observables are finally drawn.

Introduction

The nuclear Vlasov and Landau-Vlasov equations have been introduced in order to follow the time evolution of the microscopic one body distribution function $f(\vec{p}, \vec{p})$ in the phase space symplectic manifold defined at the Hartree-Fock and extended Hartree-Fock level. Properties and procedures for the determination of 
approximate solutions have been widely discussed during this conference, especially in the B. Remaud's talk. In the table 1 , we sketch the salient features characterizing the two main approches to these nuclear kinetic equations available in the literature. A nice derivation of these equations can be found, on the other hand, in R. Malfijet's contribution and in reference [1]. It turns out that the real and imaginary parts of the g-matrix enter in the mean field term and the collision term respectively. The energy and density dependence of the effective nucleon-nucleon interaction finds there its justification when one deals with the Landau-V1asov equation.

Table I - Approaches to the nuclear kinetic equation : approximate solutions, ingredients and applications.

\begin{tabular}{|c|c|}
\hline $\begin{array}{c}\text { LAMDAU-VLASOV } \\
\text { (Ref. }[2,3,4,5,6,7,18])\end{array}$ & $\begin{array}{c}\text { BOLZMANN-UEHLING-UHLENBECK } \\
\text { (Ref. }[8,9,10,11,12]) \\
\text { or } \\
\text { VLASOV-UEHLING-UHLENBECK }\end{array}$ \\
\hline $\begin{array}{l}\text { Decomposition of one-body distribution } \\
\text { function on a moving coherent state } \\
\text { basis } \\
\text { Initial nuclei in their ground state, } \\
\text { each of them being an exact station- } \\
\text { nary solution of the viasov equation } \\
\text { (initial self-consistent procedure) }\end{array}$ & $\begin{array}{l}\text { Parallel ensembles of pseudo-parti- } \\
\text { cles (nucleons) } \\
\text { average over ensembles }\end{array}$ \\
\hline $\begin{array}{l}\text { Neutrons and protons ; Coulomb inclu- } \\
\text { ded; simplified Skyrme interactions } \\
{[2,5]} \\
01 \text { interaction (long range correla- } \\
\text { tions) [7] }\end{array}$ & $\begin{array}{l}\text { Simplified Skyrme interaction } \\
\text { Momentum dependent force [13] }\end{array}$ \\
\hline $\begin{array}{l}\text { Uehling-Uhlenbeck collision term } \\
\text { with: onn (energy, density, isospin) } \\
\text { continuous relaxation }\end{array}$ & $\begin{array}{l}\text { Uehling-Uhlenbeck collision term } \\
\text { with : onn }=\text { constant } \\
\text { continuous or fluctuating }[14] \\
\text { relaxation }\end{array}$ \\
\hline $\begin{array}{l}\text { Slabs [5] } \\
\text { Spherical symmetry [3] } \\
30 \text { - desintegration [6] } \\
\text { Intermediate and low energy } \\
\text { heavy ion collisions }[4,18]\end{array}$ & $\begin{array}{l}\text { Intermediate and relativistic heavy } \\
\text { ion collisions }[8,9,10,11,12] \\
\pi \text { and } \gamma \text { emission }[15] \\
\text { Multifragmentation }[14]\end{array}$ \\
\hline
\end{tabular}

The Vlasov equation is widely used in plasma physics where the mean-field is essentially given by the electromagnetic long range interaction. In our context (the heavy ion collisions), we note that the dominant term derives from the short range strong interaction, allowing a determination of the solution which is much more stable. In this contribution, we report on a few situations where these solutions were used in order to calculate physical observables and to characterize collision processes. The fragmentation mechanism in intermediate energy heavy ion collisions is analyzed (section 1). The occurence of fusion-like processes is discussed in section 2. Particular attention is paid to particle emission in the continuuli in section 3. In section 4 , we mention some results concerning the excitation of isovector modes in heavy ion collisions near the Coulomb barrier.

\section{1. - Fragmentation mechanism}

As revealed by Landau-Vlasov calculations for collisions above $30 \mathrm{MeV} / \mathrm{u}$, the main part of the reaction cross section goes into the projectile fragmentation cross section. As a matter of fact, the partial waves corresponding to deep inelastic processes at low energy contribute at intermediate energy to an abrasion-like mechanism. However different hebaviour is found in high energy fragmentation [16] that has led to a model discussed in ref. 17. The figure 1 sketches target-1ike mass versus projectile-1ike mass correlations for the $40 \mathrm{Ar}$ $(35 \mathrm{MeV} / \mathrm{u})+{ }^{27} \mathrm{Al}$ system. A comparison with the geometrical abrasion model with a 
reduced radius $r_{0}=1.36 \mathrm{Fm}$ which fits the data (ref. 16) shows that the microscopic description accounts properly for the main correlation characterizing a fragmentation process. The target-like recoil angle (in absolute values) versus projectile-like mass correlation at $44 \mathrm{MeV} / \mathrm{u}$ incident energy is described by the dashed area in figure 2 for the experimental data and by the full 1 ine for the calculations.

$$
{ }^{40} \mathrm{Ar}(35 \mathrm{MeV} / \mathrm{u})+{ }^{27} \mathrm{Al}
$$

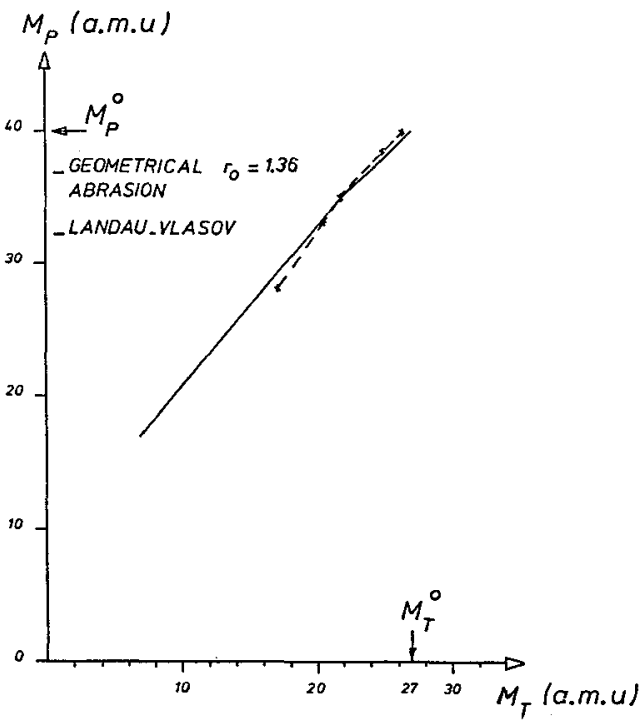

Figure 1 : Target-like versus projectile-like mass correlation in fragmentation reactions in the geometrical abrasion model (full line) and in the Landau-Vlasov calculation (dashed line) for the ${ }^{40} \mathrm{Ar}(35 \mathrm{MeV} / \mathrm{u})+{ }^{27} \mathrm{Al}$ reaction.

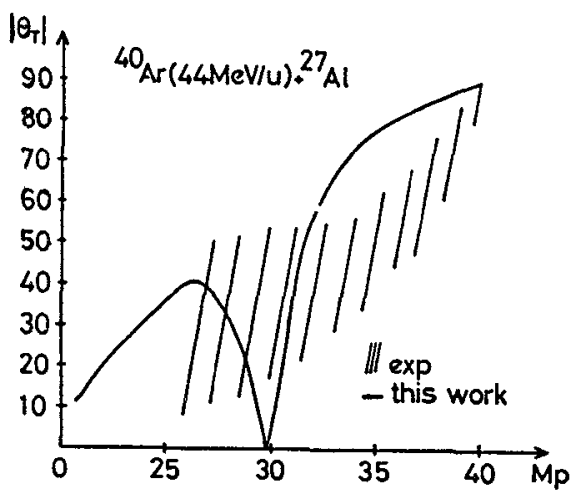

Figure 2 : Absolute value of the target-Tike recoil angle versus the projectile-like mass in $40 \mathrm{Ar}(44 \mathrm{MeV} / \mathrm{u})$ +27 Al reactions. The Landau-Vlasov calculation (full line) is compared with the data of ref [16] (dashed area).

The dip of the calculated curve corresponds to a deflection towards negative angles. The orbiting has a twofold origin : first the attractive nucleus-nucleus force generated by the mean field; secondly the one-body dissipation (nucleon exchanges) on the one hand and the two-body dissipation (collision term) on the other hand. For such peripheral reactions, it is worth mentioning that the nucleon-nucleon collisions act strongly at the surfaces of the interacting nuclei in order to damp the relative motion. The apparent discrepancy between data and calculations in figure 2 could find its origin in the strength of the two-body collision term as far as very peripheral reactions are concerned $\left(A_{0} \sim 40\right)$. Consequentiy, it seems relevant to ask for additional experimental data for a more precise analysis of this strength. For the inean energies of fragmentation products, one can mention that the agreement between theory and experiments is reasonable for the peripheral collisions. We refer the reader to the reference [18] for details.

\section{2 - Fusion-Tike processes}

A comparison between Vlasov and Landau-Vlasov calculations should answer the question dealing with the low 1-window obtained so far in TDHF calculations (see ref. [19]). A renewal of this question was recently given by the experimental observation of a possible transparency in ${ }^{28} \mathrm{Si}+{ }^{28} \mathrm{Si}$ reactions at $12.4 \mathrm{MeV} / \mathrm{u}$ 
(ref. [20]). The calculated time evolution of the relative distance $R_{12}$ between the reaction partners in $V 1$ asov dynamics indicates that such transparency could be present in absence of residual interaction (Fig. 3). Nevertheless, the same calculation performed in Landau-Vlasov dynamics shows that this effect is just an artefact of the TDHF approximation, as already mentionned by Tohyama et a1. (ref. [21]) for the $160+160$ system.

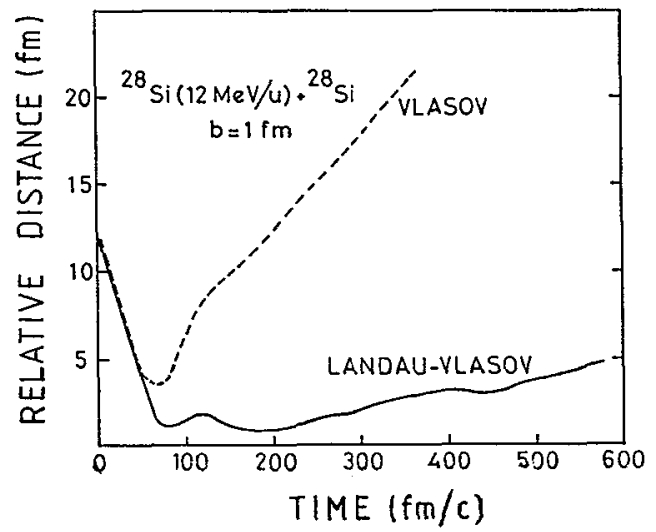

Figure 3 : A comparison between Vlasov (dashed line) and Landau-Vlasov (full line) calculations for the time dependence of the relative distance between interacting nuclei shows that the transparency in ${ }^{28} \mathrm{Si}(12 \mathrm{MeV} / \mathrm{u})+{ }^{28} \mathrm{Si}$ with a central impact parameter $b=1 \mathrm{Fm}$ is destroyed by the residual interaction.

In fact, the fusion process is very likely even at high bombarding energies (see the contribution of $\mathrm{M}$. $\mathrm{Pi}$ in this conference), at least for medium and heavy systems. For very light systems 1 ike $40 \mathrm{Ar}+27 \mathrm{Al}$ a transparency is found again above $30 \mathrm{MeV} / \mathrm{u}$ as discussed in the ref. [4] and [12]. For the $40 \mathrm{Ar}(27 \mathrm{MeV} / \mathrm{u})+$ ${ }^{238} \mathrm{U}$ reaction, for instance, it is found that large deformations of the composite system (incomplete compound system) are induced for a long time lag. This feature (Fig. 4) combined with a reasonable estimation of the linear and orbital momentum transfers (ref. [22]) provides us some confidence in our microscopic description of fusion in this energy domain.

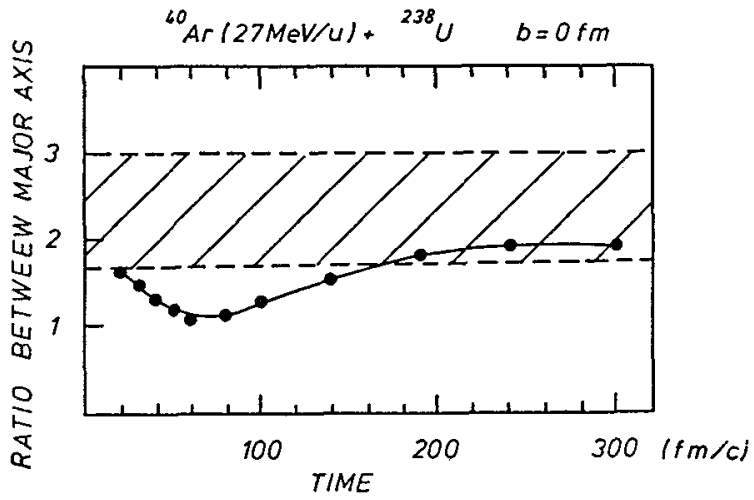

Figure 4 : Time dependence of the ratio between major axis for the composite system formed in the $40 \mathrm{Ar}$ $(27 \mathrm{MeV} / \mathrm{u})+238 \mathrm{U}$ head-on collision. Landau-Vlasov calculations (full line) are compared with data of ref. [22] dashed 1ine.

\section{3 - Particle emission into the continuum}

V1asov and Landau-Vlasov dynamics allow a direct coupling into continuum states, as soon as large collective motions are involved. It can be seen by a determination of the flux of particles (neutrons and protons) crossing a spherical surface surrounding the nuclear system. For nuclear reactions like the ${ }^{40} \mathrm{Ar}(27 \mathrm{MeV} / \mathrm{u})+{ }^{27} \mathrm{Al}$ for example, the flux exhibits two components when time increases : 
a preequilibrium component (1arge anisotropy and kinetic energy of the emitted particles) during the first stages of the collision and an evaporation component (isotropic and thermal kinetic energy of the particles). For the decay of a hot nucleus (ref. [23]), a burst of emitted particles is obtained during the first $4 \times 10^{-22 \mathrm{~s}}$ (for the $40 \mathrm{Ca}$ nucleus at $15 \mathrm{MeV}$ temperature in the case of the fig.6).

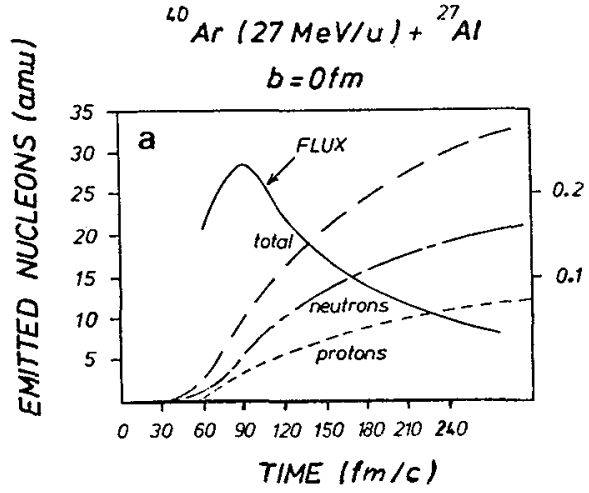

Figure 5 : (a) For a central collision, time evolution for the nucleon emission flux (right scale) and of the total number of emitted particles (1eft scale), respectively protons, neutrons and both.

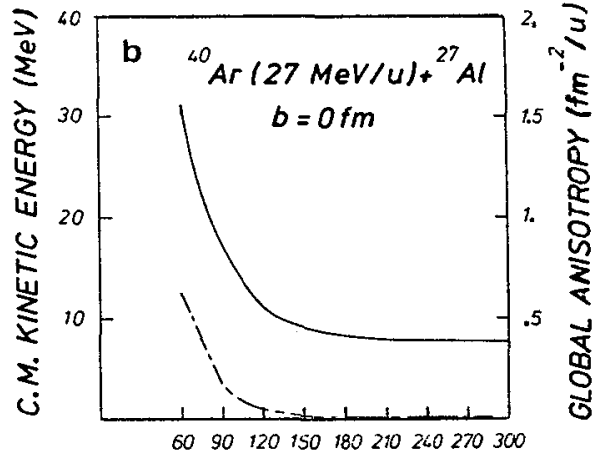

TIME $(\mathrm{fm} / \mathrm{c})$

Figure 5 : (b) For the same collision, time evolution of the instantaneous mean energy (left scale) and of the anisotropy factor (right scale) of the emitted nucleons.
Figure 6 : Decrease of the excitation energy per nucleon (upper part) and of the residual mass (lower part) of a $4^{\circ} \mathrm{Ca}$ nucleus initially heated up to a temperature of $15 \mathrm{MeV}$ (full lines) and simultaneously compressed (dashed lines).

The mass of the residual nucleus decreases smoothly afterwords, as obtained recently in spherical TDHF calculations (ref. [24]). The two previous situations illustrate that coupling into the continum is naturally contained in our description, allowing predictions concerning light particle emissions and dynamical decays.

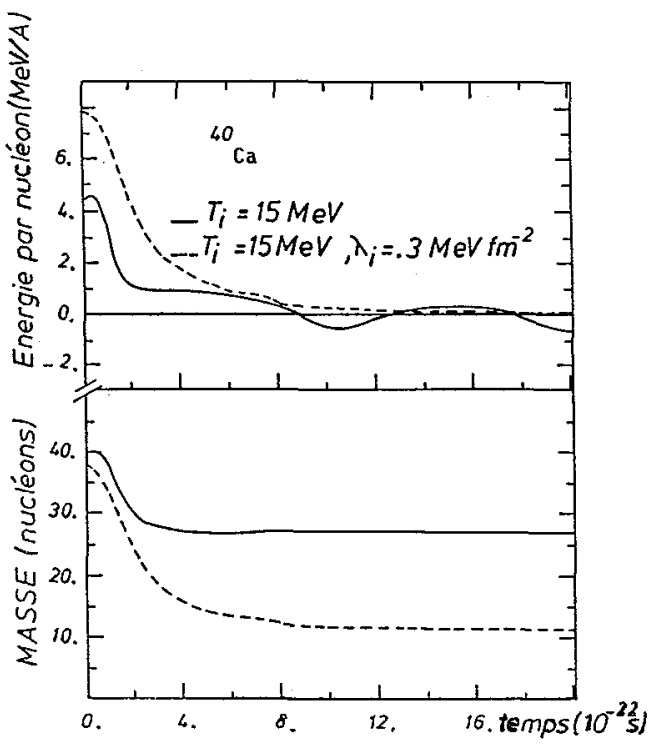

\section{5 - Isospin transfer}

The role of the isovector giant resonance of the composite system for the charge equilibration during heavy ion collisions was pointed out by the observation of the isobaric distributions in deep inelastic reactions (ref. [25]). Its excitation is revealed by TDHF calculations $([26,27]$ ). In figure 7 , the time evolution of the scalar product between the vector joining the neutron and proton center of mass respectively and an unitary vector along the line joining the center of mass of the 
reaction partners is drawn for the $160(5.5 \mathrm{MeV} / \mathrm{u})+40 \mathrm{Ca}$ reaction where the impact parameter $b$ is equal to $6 \mathrm{Fm}$. The longitudinal isovector dipole mode is excited in Landau-V1asov as well as in Vlasov dynamics. A time shift between the two calculations is due to the surface collisions which favour the excitation for a smaller overlap of the nuclear densities in the Landau-Vlasov calculation than in the Vlasov case. These calculations, possible only because our description accounts for the coulomb interaction, confirm that a collective mode whose characteristics have been calculated in ref. [28] is very likely responsible for the charge equilibration, at least during the first $5.10^{-22 \mathrm{~s}}$ (i.e. $150 \mathrm{Fm} / \mathrm{c}$ ).

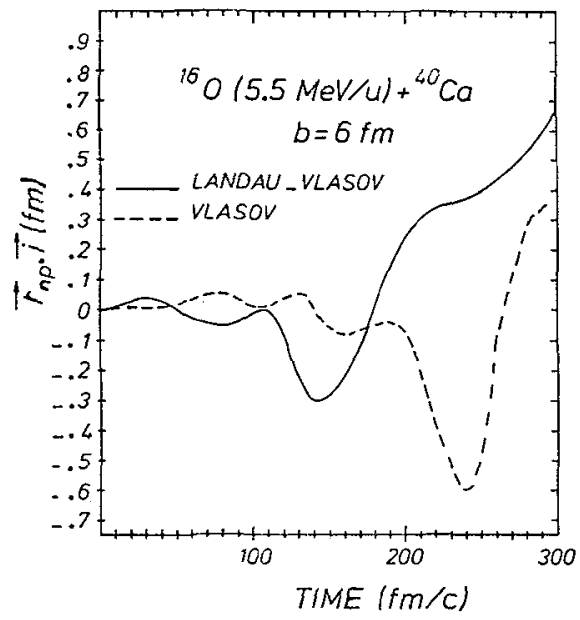

Figure 7 : Excitation of the longitudinal isovector dipole mode in $160+40 \mathrm{Ca}$ reactions near the Coulomb barrier. The oscillations are obtained as well in Vlasov (dashed line) as in Landau-Vlasov dynamics.

\section{Conclusion}

We have shown, with the help of a few examples, the richness of the semi-classical microscopic description for many physical situations occuring in low and intermediate heavy ion collisions. Further studies are in progress; they concern giant resonances at zero and finite temperature, the implementation of the momentum dependent Gogny effective interaction, the fission process at finite temperature, the gamma and pion production, the fluctuations around mean values of observables. This general project is inspired by an utterance from Gandhi : "My quest for truth taught me the beauty of compromise".

\section{Acknowledgments}

The authors are very grateful to their colleagues for their encouragements and for very fruitful discussions. We thank especially P. Schuck, M. Di Toro, J. De, J. Galin, E. Suraud and M. Pi. S. Geswend is acknowledged for having made quickly this manuscript is proper shape.

[1] W. Botermans, R. Malfliet, Phys. Lett. 171B (1986) 22.

[2] B. Remaud, C. Grégoire, F. Sébille, L. Vinet, Nuci. Phys. A447 (1985) 555c.

[3] L. Vinet, F. Sébille, C. Grégoire, B. Remaud, P. Schuck, Phys. Lett. 1728 (1986) 17.

[4] B. Remaud, C. Grégoire, F. Sébille, L. Vinet, Phys. Lett. 180B (1986) 198.

[5] C. Grégoire, B. Remaud, F. Sébille, L. Vinet, Y. Raffray, Nuct. Phys. A465 (1987) 317 .

[6] L. Vinet, C. Grégoire, P. Schuck, B. Remaud, F. Sébille, preprint GANIL 86-28, Nucl. Phys. A (in press). 
[7] B. Remaud et a1. this conference.

8. G.F. Bertsch, H. Kruse, D. Das Gupta, Phys. Rev. C29 (1984) 673.

9] H. Kruse, B.V. Jacak, H. Stöcker, Phys. Rev. Lett. 54 (1985) 289.

10] J. Aichelin, G.F. Bertsch, Phys. Rev. C31 (1985) 1730.

11. 3. Aichelin, H. Stöcker, Phys. Lett. 163B (1985) 59.

12. J. Aichelin, Phys. Rev. C33 (1986) 537.

13. C. GaTe, G.F. Bertsch, S. Das Gupta, preprint Minessota (1986) UMSI 86/57.

14. W. Bauer, G.F. Bertsch, S. Das Gupta, preprint MSUCL-582 (1986).

[15] W. Bauer, G.F. Bertsch, W. Cassing, U. Mose1, Phys. Rev. C34 (1986) 2127.

[16] R. Dayras et al., Nucl. Phys. A460 (1986) 299 and R. Coniglione et al., Nucl. Phys. A447 (1986) 95c.

[17] A. Bonasera, M. Di Toro, C. Grégoire, Nucl. Phys. A465 (1987) 317.

[18] C. Grëgoire, B. Remaud, F. Sébille, L. Vinet, Phys. Lett. 1868 (1987) 14.

[19] J.W. Negele, Rev. Mod. Phys. 54 (1982) 913.

[20] P. Decowski, E.A. Bakkum, P. Box, K. Griffioen, R. Kamermans, R.J. Mejer, Bormio (1987) and preprint Utrecht, April 1987.

[21] M. Tohyama, Nucl. Phys. A437 (1985) 443.

22 D. Jacquet, Thèse d'Etat, Orsay (1987).

23 L. Vinet, Thèse d'Université, Orsay (1986).

24 . P. Chomaz, N. Van Giai, S. Stringari, preprint IPNO/TH-87-6.

25. For a review see H. Freiesleben, J.V. Kratz, Phys. Rep. 106 (1984) 1.

$26)$ P. Bonche, C. Ngô, Phys. Lett. 105B (1981) 17.

27. M. Petrovici et al., preprint GSI-87-01 (1987).

[28] M. Di Toro, C. Grégoire, Z. Phys. A320 (1985) 321. 